\title{
How to Implement an Innovative Problem-Based Curriculum in Medical Education: Challenges and Solutions
}

\author{
Kirsti Lonka, Ph.D. \\ Director, Development and Research Unit, \\ Learning Centre, Faculty of Medicine, \\ PO BOX 61, 00014 UNIVERSITY OF HELSINKI \\ Kirsti.Lonka@helsinki.fi
}

\begin{abstract}
The Faculty of Medicine at the University of Helsinki began to evaluate and reform the curriculum of medical studies in 1994. This process resulted in Helsinki 2000, a hybrid problem-based learning (PBL) curriculum, which was introduced in 1998. When the reform was started, most teachers lacked all pedagogic training, and their understanding of the learning process was rather modest. Data from medical teachers' learning portfolios included evaluations of differents parts of their training process, structured course feedback, and the development of the teaching philosophy. Methods which promoted teachers' experiential learning and reflection on their own work appeared promising in university teacher training.
\end{abstract}

Keywords: educational reform, higher education, teacher beliefs and practices, teacher learning

\section{The Challenge of Problem-Based Learning}

Medical education is in the constant process of change, which makes it a challenging and fascinating field of study. In Finland, typical proposals for the improvement of undergraduate medical education have involved teaching the practical skills needed in general practice and closer integration of pre-clinical and clinical studies (Hyppölä et al., 1996). Lindblom-Ylänne \& Lonka (1999) explored the problems related to traditional medical curriculum. They found that the learning environment of a traditional medical school gave misleading cues about how to study efficiently and forced many students to study in inadequate ways, pushing them towards externally regulated and superficial learning. Apparently, many medical students had problems in meaningful learning.

Problems in traditional medical school have been explained by means of the so-called two-world hypothesis (Patel, Evans, \& Groen, 1989) - also known as the knowledge encapsulation problem - which may be summarized as a lack of basic scientific concepts in reasoning about medical problems. Van den Wiel (1997) suggests that a combination of practical experience with real patients, tutorial groups and self-study may lead to improved integration of knowledge, so that more coherent networks of knowledge become associated with the relevant clinical concepts. The profession in its current form calls for scientific thinking skills and a capacity for life-long learning. Previous research indicates that PBL students are more likely to study for meaning and less likely to study for reproduction of information (Albanese \& Mitchell, 1993). This may be one of the reasons why PBL has spread into an increasing number of medical faculties, including older and mor e traditional universities (Lowry, 1993).

Problem-based learning (PBL) is a system of medical education pioneered and developed in McMaster University, Canada and Maastricht University, the Netherlands, for example. The practices vary, but the essentially PBL is an instructional method that uses real-world problem as the context for an in-depth investigation of core content (e.g., Boud \& Feletti, 1997). The problems that students face are ill-structured and cannot be solved by using standard formulas. Instead, the students must use inquiry and reasoning.

\section{Implementing Problem-Based Learning (PBL) in Helsinki}

University of Helsinki began to evaluate and reform the curriculum of medical studies in 1994. This process resulted in Helsinki 2000, a hybrid problem-based learning (PBL) curriculum, which was introduced in 1998. When the reform was started, most teachers lacked all pedagogic training, and their understanding of the learning process was rather modest. It was imperative to train them in the application of new instructional procedures. They had to learn a new approach to teaching, because PBL requires medical teachers to internalize a view of students as active constructors of knowledge. To support the change process, the Development and 
Research Unit was founded in 1996 as a part of the Learning Centre, Faculty of Medicine. Its main responsibilities are the training of medical teachers and developing a course feedback system. Its speciality is are multidisciplinary co-operation and resear on the learning process by using psychological theories and methods. In 1998, an intensive staff development and teacher training program was started.

\section{Methods}

The participants were 45 medical teachers who filled in a 5-page semi-structured learning portfolio: 20 teachers in a 9-month long-term training program, 12 biomedical teachers in 4-month tutor-training, and 13 clinical teachers in 2-month tutor-training in 1998. One of the educational methods was called PBL tutorial laboratory. This procedure includes a group of medical teachers (a PBL group), and experienced peer teacher (the tutor) and a pedagogical expert (a mentor). In the first small group session, a model of efficient tutorial is being presented and discussed, The peer teacher acts as the tutor of the group and the mentor remains the observer. In the next sessions, the tutor is chosen among the group members, whereas the peer teacher and the mentor act as outside observers. At the end of the session, a 15-minute evaluation takes place where: 1) the groups evaluates itself, 2) the peer teacher evaluates the contents and products of learning and gives feedback to the tutor, and 3) the mentor gives interpretation of the group process.

Structured evaluations collected from participants included questions on how well the following aspects were learned (on the scale 1-5): a) How to activate students, b) The method of problem-based learning, c) How to support the learning process, d) Group work skills, e) Communication skills and f) Feedback strategies. The teachers also answered open-ended questions concerning the impact of the method on their teaching. Their descriptions of their teaching philosophies were analyzed qualitatively.

\section{Results and Discussion}

The clinical teachers gave higher evaluations on all quantitative measures than biomedical teachers, but the only significant difference was in learning the method of PBL. Results from the open-ended questions showed that the tutorial laboratory sessions improved teachers' cooperation across the departments. It brought new teaching ideas for shared use. It improved teacher's ability to evaluate and develop their teaching and helped in coping with the curriculum change process. The impact of training on teaching philosophies varied a lot, and best evaluations were given by those teachers who had adopted constructive ideas of learning. Methods which promote teachers' experiential learning and reflection on their own work appeared promising in university teacher training. Understanding of group dynamics is also essential in PBL, especially when dealing with the obstacles of the learning process. Using peer teachers and mentors provided a method which is very functional in promoting these objectives. Problem-based learning is not originally a heavily theoretically-driven approach, but rather, a practical way to develop highly competent practitioners (Boud \& Feletti, 1997). However, the development of teachers' conceptions of learning during pedagogical training and should be addressed more closely in the future.

\section{References}

Albanese, M.A., \& Mitchell, S. (1993). Problem-based learning: A review of literature on its outcomes and implementation issues. Academic Medicine, 68, 52-81.

Boud, D. \& Feletti, G. (1997, Eds.), The challenge of problem-based learning. Second Edition. London, UK: Kogan Page

Hyppölä, H., Kumpusalo, E., Neittaanmäki, L., Mattila, K., Virjo, I., Kujala, S., Luhtala, R., Halila, H., \& Isokoski, M. (1996). Where should special attention be paid in undergraduate medical education? Two surveys among Finnish doctors. Medical Education, 30, 31-37.

Lindblom-Ylänne, S. \& Lonka, K. (1999). Individual ways of interacting with the learning environment - Are they related to study success? Learning and Instruction, 9, 1-18.

Lowry, S. (1993). Making change happen. British Medical Journal, 306, 320-322.foundations of cognition (pp. 394-411). Cambridge: University Press.

Patel, V.L., Evans, D.A., \& Groen, G.J. (1989). Biomedical knowledge and clinical reasoning. In D.A. Evans \& V.L. Patel (Eds.), Cognitive science in medicine: Biomedical modeling. (pp. 53-112) Cambridge, MA: The MIT Press.

van de Wiel, M. W. J. (1997). Knowledge encapsulation. Studies on the development of medical expertise. Doctoral dissertation. University of Maastricht. 